\title{
O CONCEITO ESFERA PÚBLICA NO PENSAMENTO HABERMASIANO
}

\begin{abstract}
Resumo
O texto intitulado Mudança estrutural da esfera pública, publicado em 1962 e que reproduz sua tese de habilitação, marca o início da multifacetada e complexa obra habermasiana. Ele configura, além disso, um dos conceitos centrais e estruturantes que acompanham a obra de Habermas como um todo. Dois anos mais tarde, em 1964, ele redigiu um novo texto, bastante resumido, sobre a esfera pública para um léxico, no qual condensa, reorganiza e, inclusive, remodela algumas idéias expostas na Mudança estrutural da esfera pública de 1962. Tomei esse texto como guia para entender as ideias nem sempre tão claras expostas no texto de 1962. Deter-me-ei em quatro pontos: a) $\mathrm{O}$ conceito de esfera pública nesta fase inicial de seu pensamento. b) A correta compreensão do conceito de esfera pública implica uma análise histórica. c) $\mathrm{O}$ modelo liberal de esfera pública. d) A esfera pública nas democracias de massa do Estado social.
\end{abstract}

Palavras-chave: Esfera Pública. Teoria Crítica. Teoria Democrática.

\begin{abstract}
The text entitled Structural Change of the Public Sphere, published in 1962 and which reproduces its habilitation thesis, marks the beginning of the multifaceted and complex Habermasian work. It also constitutes one of the central and structuring concepts that accompany the work of Habermas as a whole. Two years later, in 1964, he wrote a rather abridged text on the public sphere for a lexicon in which he condenses, reorganizes, and even reshapes some of the ideas set out in the 1962 Structural Change of the Public Sphere. I have taken this text as a guide to understand the ideas not always so clear in the text of 1962. I will dwell on four points: a) The concept of the public sphere in this initial phase of his thinking. b) The correct understanding of the concept of the public sphere implies a historical analysis. c) The liberal model of the public sphere. d) The public sphere in the mass democracies of the social state.
\end{abstract}

Keyword: Public Sphere. Critical Theory. Democratic Theory.

\section{CONSIDERAÇÕES GERAIS}

\subsection{CONCEITO GENÉRICO DE ESFERA PÚBLICA}

Inspirando-se no conceito de "publicidade", kantiano, Habermas (1973) toma como ponto de partida a idéia de que a esfera pública surge como comunicação que se forma em espaços da vida social humana permitindo a formação de uma opinião pública focada em temas e assuntos de interesse geral.

Esta obra está licenciada sob uma Licença Creative Commons Atribuição 4.0 Internacional (CC BY-NC-AS 4.0). LOGEION: Filosofia da informação, Rio de Janeiro, v. 5, 2018, Edição Especial, p. 84-96 
Esses espaços irrompem na sociedade burguesa do séc. XVIII, estando abertos, em princípio, a todas as pessoas privadas que se reúnem em público e expressam livremente sua opinião sobre assuntos de interesse geral. E nesse caso, elas não agem apenas na qualidade de homens de negócios ou enquanto funcionários que tratam de seus interesses privados. Nem apenas enquanto membros do direito submetidos às regras e instruções de uma burocracia estatal (HABERMAS, 1973, p. 61).

Esta esfera - que abrange um público de pessoas privadas que analisam criticamente e discutem publicamente questões sociais e, em especial, o exercício do poder político - se constitui como um espaço situado entre uma sociedade civil, de um lado, e um poder organizado na forma de Estado de outro. Enquanto portadora da opinião pública, esta esfera teve de imporse, inicialmente, contra o poder dos monarcas. E a partir daí ela conseguiu abrir a perspectiva de um controle democrático da atividade política em geral. É interessante lembrar que o novo elemento da esfera pública só conseguiu ter acesso à sociedade burguesa do séc. XVIII graças a uma determinada constelação de interesses (HABERMAS, 1973, p. 62).

\subsection{HISTÓRIA DA ESFERA PÚBLICA}

Habermas (1973) distingue dois momentos cruciais na história desse conceito, a saber: a fase da esfera pública medieval ou pré-liberal e a fase da esfera pública liberal.

\subsubsection{Uma esfera pública pré-liberal, medieval.}

Nesta fase não havia propriamente uma esfera pública em sentido estrito, isto é, como domínio próprio e distinto da esfera privada. Mas havia uma representação pública do poder, visto que o senhor feudal se apresentava como incorporação de um poder superior (HABERMAS, 1973, p. 63). E nesse sentido, a representação de um determinado mandatário ou de uma nação pouco ou nada tinha a ver com uma esfera pública representativa. Os príncipes podiam até representar o seu poder, porém, eles apenas o representavam perante o povo, não para o povo. Não havia, por conseguinte, nenhum tipo de esfera pública em sentido estrito, isto é, como domínio próprio e distinto da esfera privada.

Entretanto, Habermas (1973), destaca que os poderes feudais, isto é, o poder da Igreja, dos principados e dos estamentos dos senhores, vai se diluindo gradativamente durante um longo e tortuoso processo. Até que, no final do século XVIII, eles se distribuem em duas partes ou setores sociais opostos, a saber:

LOGEION: Filosofia da informação, Rio de Janeiro, v. 5, 2018, Edição Especial, p.84-96 
- O setor privado

- O setor público

E nesse momento entra em cena um novo elemento, a saber, a liberdade de religião. A Igreja continua a existir, porém, apenas como uma corporação entre outras, a qual goza da garantia de um direito público. Habermas (1973), ressalta que a liberdade de religião assegura a primeira esfera ou espaço de autonomia privada.

No decorrer do processo de passagem da esfera, "esfera pública pré-burguesa" para a liberal, as instituições do poder público, tais como os Estados nacionais e territoriais, as burocracias, os exércitos, as igrejas, as jurisprudências, etc., tornam-se independentes da esfera privada do castelo, ou do "burgo".

De outro lado, desenvolvem-se corporações que formam uma esfera pública capaz de representar a "sociedade dos burgos" ou "sociedade burguesa", a qual se contrapõe, enquanto espaço genuíno de autonomia privada, ao poder do Estado (HABERMAS, 1973, p. 63-64).

No final desse processo, o poder público se consolida como um "oposto", isto é, como um "outro" em relação aos seus subalternos que lhe estão sujeitos e que encontram nele uma determinação meramente negativa. Trata-se, nesse caso, de "pessoas privadas" que não fazem parte da administração pública.

Para Habermas (1973), é interessante notar que neste caso o conceito de "público" não se refere mais a uma única pessoa investida de autoridade, mas a uma espécie de "aparelho" que possui o monopólio do uso legítimo do poder, o qual é regulado mediante competências. A partir de agora temos, pois:

- De um lado, um Estado investido de poder público.

- De outro, pessoas privadas que são destinatárias desse poder público.

Nesta relação de oposição entre pessoas privadas, de um lado, e Estado, de outro, a sociedade se destaca nitidamente do poder público. Além disso, ela se torna assunto de interesse comum à medida que a reprodução da vida humana começa a extrapolar os limites estreitos de uma economia doméstica privada.

Tal fato tornou possível a formação de uma esfera pública de pessoas privadas que se reúnem inicialmente nos burgos a fim de formar um público. Elas pretendem opor ao poder do Estado a esfera pública que se forma nos jornais, em textos de cunho moral e noutros meios de comunicação, para discutir sobre as regras de comércio que devem prevalecer na sua esfera privatizada de trabalho e na troca de mercadorias (HABERMAS, 1973, p. 64). 
Entretanto, o resultado mais surpreendente destes desdobramentos se condensou no surgimento de um elemento totalmente novo, a saber: o médium da discussão pública no contexto do modelo liberal da esfera pública.

\subsubsection{O médium da discussão pública no âmbito da esfera pública liberal.}

O médium da discussão pública no âmbito do modelo liberal não encontra precedentes na história. Antes desse momento, isto é, na fase pré-liberal, os estamentos e seus príncipes conseguiam elaborar acordos mediante os quais pretensões de poder eram reguladas caso a caso. Mesmo assim, o poder enquanto tal não era posto em discussão. Nesse momento, porém, passa-se a questionar a própria base de legitimação do poder. Não se trata, pois, de uma simples troca da base de legitimação por outra, Habermas (1973), cita como exemplo a Inglaterra, onde o poder dos príncipes é relativizado pelo Parlamento.

Explicando de outra forma: os moradores dos burgos ou burgueses - que eram considerados membros do terceiro estamento - eram pessoas privadas que, enquanto tais, não dominavam nem governavam. Por isso, suas pretensões de poder dirigidas contra o poder público não se dirigiam diretamente contra um "poder concentrado" a ser dividido entre eles.

Agora, porém, eles simplesmente tomam outro caminho, o qual lhes permite, de certa forma, burlar o princípio do poder constituído: O público dos burgos opõe ao poder constituído um princípio de controle na forma de um princípio da publicidade. Tal princípio não substitui simplesmente uma base de legitimação por outra. Mesmo assim, ele consegue modificar o próprio conceito de poder e de dominação enquanto tal (HABERMAS, 1973, p. $65)$.

Habermas (1973), observa que as primeiras constituições modernas copiam esse modelo da esfera liberal burguesa quando tratam dos direitos fundamentais. Esses direitos garantem, em primeiro lugar, "a sociedade como esfera de autonomia privada". Em segundo lugar, "o poder público limitado" a umas poucas funções. E em terceiro lugar, "o espaço das pessoas privadas que se reúnem formando um público”. Esse espaço se situa entre dois polos: o da autonomia privada e o do poder público. São essas pessoas, agora consideradas cidadãos de um Estado, que fazem a mediação entre o poder público do Estado e as necessidades da sociedade burguesa. 
Essa transposição da autoridade política para o médium da esfera pública pode ser interpretada como racionalização da autoridade política, a qual deve pautar-se por um interesse geral.

No contexto da esfera pública burguesa, a salvaguarda do interesse geral pressupunha as seguintes condições:

- Uma sociedade onde a troca de mercadorias fosse livre (livre mercado).

- Uma sociedade onde o intercâmbio entre as pessoas na esfera pública fosse livre de coação política.

\subsubsection{Os jornais e periódicos como portadores, canalizadores e mediadores da opinião pública.}

$\mathrm{Na}$ sociedade liberal eles deixam de ser simples veículos de notícias para se transformarem em porta-vozes da opinião pública e meios de luta das políticas partidárias. Isso teve uma conseqüência importante na própria organização interna das empresas jornalísticas: dado o volume e a diversidade das notícias a serem publicadas, criou-se a necessidade da figura de um redator que as selecionasse. Isso fez com que os jornais deixassem de ser simples veículos para a venda de novas notícias para se transformarem em "instâncias raciocionantes" que negociam com a opinião pública. A partir daí os editores garantiam ao jornal uma base comercial. E a imprensa, que antes era simples órgão de transferência de informações, passa a ser incrementadora e mediadora de discussões públicas políticas (HABERMAS, 1973, p. 66).

E as figuras políticas passam a utilizá-la para seus fins particulares, especialmente em épocas de revolução. Habermas (1973), constata, por exemplo, que em 1848 todo político de certa envergadura tinha o seu próprio clube e quase todos tinham o seu jornal (Journal) e destaca que entre fevereiro e maio desse ano surgiram 450 clubes e 200 jornais!

É possível imaginar, segundo Habermas (1973), que o aparecimento de um jornal político podia ser tido como um engajamento na luta por um espaço de liberdade da opinião pública, ou seja, como uma luta pela esfera pública como princípio.

A partir do estabelecimento do Estado burguês de direito na Inglaterra, na França e nos EEUU no século XIX (1830-1840), a imprensa deixa de ser simplesmente polêmica para se configurar como um jornalismo de pessoas privadas que prestam serviços públicos mediante meios de comunicação de massa. Isso implica, no entanto, uma mudança estrutural na esfera pública que vai ser perpassada por interesses privados (HABERMAS, 1973, p. 66-67). 


\subsubsection{Mudança estrutural da esfera pública burguesa nas democracias de massa dos Estados sociais.}

Habermas (1973), considera que o modelo liberal da esfera pública é, acima de tudo, instrutivo do ponto de vista da pretensão das normas. Porém, não é aplicável às novas condições de uma democracia de massas que se configura, do ponto de vista político, como Estado social e, do ponto de vista econômico, como um sistema industrial globalizado. Nesse novo contexto, a esfera pública burguesa perde sua exclusividade social.

1.2.4.1. Enfraquecimento da esfera pública burguesa

Entretanto, um novo elemento entra em cena, uma vez que os conflitos que durante a vigência da esfera pública burguesa tinham sido reprimidos na esfera privada, eclodem na esfera pública. Além disso, necessidades de grupos que não podiam esperar nenhum tipo de satisfação em um mercado que se regulava a si próprio, tendem agora a buscar uma regulação mediante o Estado. Isso provoca transformações na esfera pública. De um lado, ela se vê pressionada a regular essas novas exigências e, com isso, ela se torna um espaço propício para uma concorrência rude e, às vezes violenta, entre interesses.

De outro lado, as leis surgem agora "sob a pressão das ruas" e dificilmente podem ser entendidas como resultado de um consenso de pessoas privadas que discutem em público. Elas passam a ser, ao invés disso, fruto de um compromisso entre interesses privados conflitantes entre si (HABERMAS, 1973, p. 67).

Disso resulta um novo tipo de entrelaçamento entre domínio público e privado: As instâncias políticas assumem funções sociais na esfera do trabalho e do comércio.

1.2.4.2. Mudança estrutural da esfera pública.

O entrelaçamento entre domínio público e privado no Estado do bem-estar social equivale inicialmente a um enfraquecimento da esfera pública. Isso porque as grandes organizações necessitam agora do assentimento das massas. Esse fato novo as leva a 
desenvolver uma espécie de esfera pública "publicitária" ou de fachada, o que equivale a uma emasculação das funções críticas da esfera pública.

Isso fica claro quando se tem em mente as funções atribuídas à "publicidade" nas duas fases da esfera pública:

- Antes da mudança estrutural a publicidade era tida como razão pública, ou melhor, como um espaço racional público, como um fórum da opinião pública, onde era possível avaliar a razoabilidade de atitudes de pessoas e, inclusive, rever decisões políticas.

- Após esta mudança, a "publicidade" é emasculada e passa a ser utilizada para auxiliar a política de grupos interessados. Enquanto "publicity" ela confere prestígio a pessoas ou coisas em um clima de opinião não pública. Quebra-se assim o público de pessoas privadas que permitia uma interação espontânea entre elas.

1.2.4.3. Redirecionamento do princípio da esfera pública burguesa no Estado social.

O Estado social redireciona a esfera pública à luz de direitos fundamentais. Ou seja, ele estende a esfera pública a todas as organizações sociais. Com isso, ele cria novo público formado por pessoas privadas organizadas (HABERMAS, 1973, p. 68). Esse parece ser o melhor caminho para a legitimação de compromissos políticos. Uma vez que somente pessoas privadas organizadas poderiam participar efetivamente no processo da comunicação pública pelos canais de uma esfera pública interpartidária.

Habermas pensa, contudo, que esse redirecionamento constitui, de um lado, uma ameaça à idéia de esfera pública entendida como racionalização da dominação no médium de discussões públicas entre pessoas privadas.

De outro lado, porém, é possível reinterpretar essa base modificada da esfera pública como "racionalização do poder político sob o controle recíproco de organizações rivais que dependem de esfera pública, seja na sua estrutura interna, seja no trato com o Estado" (HABERMAS, 1973, p. 68).

Não é possível acompanhar aqui os desdobramentos da reflexão habermasiana sobre esse ponto. É conveniente, todavia, lembrar que as ideias e argumentos desenvolvidos no trabalho sobre a esfera pública burguesa encontraram eco em muitos pensadores a partir dos anos 70 do século XX. Mas também foram alvo de muitas críticas. Cito como exemplo a crítica do historiador inglês Peter Burke, a qual foi publicada na Folha de S. Paulo em 14 de março de 2002, por ocasião do quadragésimo aniversário da publicação de Mudança estrutural da esfera pública.

LOGEION: Filosofia da informação, Rio de Janeiro, v. 5, 2018, Edição Especial, p.84-96 
De um lado, Burke (2002), destaca o fato de Habermas ter afirmado que o século XVIII foi o período crucial na ascensão da esfera pública como uma zona para debates e discursos sobre ideias, instituições e políticas. Ele escreve, além disso, que a característica mais original do livro consiste no realce atribuído à contribuição para a discussão de questões públicas em instituições urbanas (burguesas) informais como, por exemplo, salões, sociedades de debate, cafés, etc. e em instituições formais tais como o Parlamento inglês.

De outro lado, Burke formula três críticas ao texto habermasiano: a) Habermas começou a sua história da esfera pública tarde demais uma vez que considera o século XVIII como início, ignorando o lugar do debate político público nas cidades-Estado italianas do século $\mathrm{XV}$, especialmente em Florença. b) Habermas formula as perguntas corretas. Suas respostas, no entanto, são simples demais. c) Habermas idealiza a esfera pública e as instituições de comunicação. Ele não chama a atenção para o fato de que os meios de comunicação podem ser utilizados como meios de manipulação da opinião pública.

Habermas reconhece posteriormente esse idealismo e tenta corrigi-lo à luz de uma teoria do discurso (HABERMAS, 2005, p. 14). (cf. Phil. Texte, IV, 2005, 14).

Vale a pena citar na íntegra o parágrafo final do texto de Burke:

Graças a essas novas instituições, é mais fácil pensar sobre questões públicas em termos globais do que o era 40 anos atrás, e é mais fácil também criticar os pontos de vista de Habermas como demasiado limitados. Mas essas críticas seriam impossíveis se Habermas não houvesse produzido sua formulação original. Nesse sentido nós estamos pensando com ele mesmo quando estamos contra ele, e por essa razão o quadragésimo aniversário de seu estudo merece ser comemorado (BURKE, 2002).

Não pretendo aprofundar, aqui, as críticas a esse texto dedicado à estruturação da esfera pública a partir do século XVIII, uma vez que O meu principal interesse consiste em mostrar que o conceito esfera pública vai ser decisivo não somente para a configuração das convicções políticas do cidadão Habermas, nem somente para o desenvolvimento de uma teoria política, mas também, e principalmente, para a articulação da sua teoria do agir comunicativo como um todo. E nesse contexto o conceito de esfera pública bem como seu correlato, a democracia, desempenham um papel fundamental.

\section{O PAPEL DA ESFERA PÚBLICA NOS DESDOBRAMENTOS DA FILOSOFIA HABERMASIANA COMO UM TODO.}

A relevância da esfera pública no pensamento habermasiano deriva do fato de ele tomar a natureza social do homem como ponto de partida de suas reflexões filosóficas. Segundo ele, para reconhecer o caráter específico da natureza humana é necessário traduzir literalmente LOGEION: Filosofia da informação, Rio de Janeiro, v. 5, 2018, Edição Especial, p.84-96 
a famosa fórmula de Aristóteles, segundo a qual o homem é um zoon politikon para fórmula seguinte, mais adequada ao seu sistema de pensamento: "o homem é um animal político, isto é, um animal que existe em uma esfera pública" dado o fato de que ele é "um animal que desenvolve as competências que o transformam em uma pessoa graças à inserção originária em uma rede pública de relações sociais”. (HABERMAS, 2005, p. 17).

Dessas pressuposições habermasianas é possível tirar quatro conclusões que convém reter na mente quando tentamos compreender o papel e a importância da esfera pública no seu pensamento:

1) O homem depende de uma cultura pública compartilhada intersubjetivamente com outros parceiros.

2) Os homens são capazes de aprender uns dos outros. E isso somente é possível na esfera ou no espaço público de um meio cultural estimulante.

3) A reflexão sobre a natureza social do homem nos obriga a sublinhar a constituição intersubjetiva do espírito humano. Porquanto os seres humanos dependem profundamente uns dos outros devido à intersubjetividade, a qual constitui uma espécie de "espírito objetivo":

No interior do sujeito individual reflete-se um exterior. Pois o espírito subjetivo adquire estrutura e conteúdo através de uma acoplagem ao espírito objetivo que reside no trato intersubjetivo entre sujeitos naturalmente socializados (HABERMAS, 2005, p. 18).

4) O sujeito se torna pessoa ao entrar no espaço público de um mundo social que é, também, mundo da vida, e que o espera, por assim dizer, de braços abertos.

Nesse contexto da obra habermasiana, o espaço público ou esfera pública aparece como um fenômeno geral que se manifesta nas interações humanas, inclusive nas mais simples, como é o caso da fala entre Ego e Alter.

É interessante notar as razões que o levam a se concentrar nesse fenômeno: De um lado, ele tem em mente o espaço público em geral porque este possui uma "força misteriosa" que deriva da intersubjetividade, a qual é capaz de reunir coisas distintas sem as assimilar umas às outras (HABERMAS, 2005, p. 25).

De outro lado, e isso é muito importante, ele está interessado nos diferentes tipos de esferas públicas particulares porque elas são capazes de revelar anomias, rupturas ou patologias no caso de uma socialização repressiva. 


\subsection{A ESFERA PÚBLICA NAS SOCIEDADES COMPLEXAS.}

Apesar da importância atribuída à esfera pública como fenômeno geral em sociedades democráticas, Habermas argumenta que, nas atuais sociedades complexas e multiculturais, a integração social necessita, além disso, de uma esfera pública política. Porque tais sociedades, nas quais os cidadãos não podem conhecer-se pessoalmente, somente podem ser mantidas coesas por uma solidariedade abstrata entre cidadãos de um Estado, a qual é mediada pelo direito (HABERMAS, 2005, p. 25).

Habermas trabalha aqui com dois níveis distintos de análise:

- Em um nível mais geral, a esfera pública constitui um fenômeno que Habermas qualifica às vezes como "misterioso" porquanto se confunde com a própria natureza social do homem.

- Em um nível político/democrático, porém, ela constitui um espaço racional público e livre onde é possível discutir sobre qualquer tema político, social ou cultural, etc. Esta esfera pública política se apresenta atualmente, segundo ele, sob duas formas:

a) Como espaço de auto-apresentação de personalidades públicas tais como atores, modelos, artistas, políticos, músicos, etc., com a finalidade de uma auto-representação pessoal. Seu público é constituído de assistentes e/ou ouvintes, espectadores, etc., que concentram seus olhares no astro, na estrela da novela, no personagem político, etc. É importante salientar que neste espaço, onde a esfera pública e a privada se misturam entre si, o que conta não são os argumentos, apenas olhares.

b) Como espaço onde se participa de controvérsias mediante opiniões e argumentos racionais. Sua finalidade reside na busca de um entendimento (Verständigung) sobre um tema que pode ser político, científico, literário, artístico, religioso, etc. Seu público é constituído de falantes e ouvintes de variados tipos que se interrogam, procuram dar respostas ou trocam argumentos. Neste espaço, a esfera pública e a privada não se confundem nem se misturam: sua relação é complementar (HABERMAS (ZNR), 2005, p. 13).

\section{SOBRE A UTILIDADE DO CONCEITO HABERMASIANO DE ESFERA PÚBLICA NO QUADRO DAS DISCUSSÕES ATUAIS.}

Segundo Bernhard Peters (2001, p. 656), as pesquisas de Habermas sobre a esfera pública discursiva influenciaram profundamente dois novos campos de pesquisa. Em primeiro lugar, teorias da assim chamada democracia deliberativa que se ocupam da problemática 
envolvendo ordens políticas transnacionais, tais como, por exemplo, a União Européia, as quais conferem especial importância à esfera pública (Cf. WINGERT; GÜNTHER, 2001. p. 655 677).

De outro lado, existe uma série de pesquisas empíricas que se orientam por uma concepção abrangente de esfera pública. Algumas delas, inclusive, chegam a se orientar diretamente pelo modelo habermasiano.

No seu artigo, Peters (2001), discute certos resultados dessas pesquisas na perspectiva de sua relevância para concepções normativas do conceito de esfera pública enquanto "deliberação pública" e democrática. É interessante destacar que as teorias da democracia deliberativa entendem a "deliberação pública" como uma disputa argumentativa sobre questões da vida coletiva, da qual todos podem participar livremente (PETERS, 2001, p. 656).

Esse tipo de esfera pública permite, de um lado, incrementar a racionalidade da formação pública da opinião e da vontade dos cidadãos, o que implica não somente a racionalização das argumentações públicas, mas também o auto-esclarecimento dos participantes. De outro lado, a esfera pública deliberativa constitui uma fonte importante da integração social e da legitimidade política (PETERS, 2001, p. 657).

Assim, Peters (2001), conclui suas críticas pontuando que, apesar dos problemas inerentes ao conceito de esfera pública, ele é imprescindível no quadro atual tendo em vista que um discurso público pode influenciar indiretamente as opiniões, as idéias e convicções do público. Pois, graças a ele, enquanto certos posicionamentos e argumentos tornam-se, aos poucos, insustentáveis, perdendo sua influência ou desaparecendo por completo do estoque das argumentações públicas, outros argumentos, problemas ou ideias podem surgir, os quais vão tomando forma e se impondo nos debates públicos.

E pode ser que esse processo também produza elementos de convergência ou de consenso em um sentido amplo até o ponto em que certas idéias, convicções e princípios normativos passam a ser aceitos como comprovados e convincentes mesmo que não tenha sido declarado um consenso explícito (PETERS, 2001, p. 667).

Vale a pena apresentar alguns exemplos históricos de mudanças de convicções do público provocadas por argumentações discursivas em esferas públicas:

- O modo conceber as relações entre os sexos.

- O modo de interpretar a educação.

- O feminismo.

- Questões relativas ao meio ambiente. 
- Questões referentes aos direitos de minorias.

Podemos concluir, pois, com Bernhard Peters (2001), que os efeitos potenciais da esfera pública aparecem mais em transformações graduais e difusas dos repertórios culturais, dos estoques de argumentos públicos do que propriamente em resultados consensuais imediatos de uma disputa política. Isso porque a sua eficácia se comprova melhor em processos de aprendizagem no longo prazo.

Gostaria de finalizar esta exposição lembrando que Habermas tem uma visão bem definida quanto ao papel específico do intelectual filósofo em relação à atual esfera pública. Ele chega a elaborar, inclusive, uma espécie de "código de deveres" do intelectual que participa de debates públicos:

1) O intelectual deve fazer uso público do saber profissional de que dispõe enquanto filósofo, historiador, físico, etc. Esse uso deve resultar de uma decisão dele mesmo, não de uma incumbência recebida de outros.

2) Deve manifestar-se em público tendo consciência de sua falibilidade.

3) Deve limitar-se a temas relevantes.

4) Deve aduzir informações objetivas e os melhores argumentos possíveis.

5) Deve tentar melhorar o baixo nível das controvérsias públicas atuais.

6) Ele pode assumir dois papeis distintos que ele deve separar cuidadosamente, a saber: a) Seu papel enquanto profissional que utiliza a razão, a palavra e o discurso. b) Seu papel como pessoa pública influente. Não deve aproveitar-se dessa influência para transformá-la em poder ou para ocupar cargos públicos. Isso porque, ao ocuparem cargos públicos, os intelectuais deixam de agir como intelectuais. "O estado de uma democracia pode ser auscultado pelas pulsações da esfera pública" (HABERMAS (ZNR), 2005, p. 25). 


\section{REFERÊNCIAS}

BURKE, Peter. A esfera pública 40 anos depois. Folha de S. Paulo, São Paulo, Caderno Mais, p. 13, 14 mar. 2002.

HABERMAS. Jürgen. Kultur und kritik: verstreute aufsätze. Frankfurt am Main: Surhkamp, 1973.

. Öffentlichkeit. In: FRAENKEL, Ernst; BRACHER, Karl Dietrich (eds.). Fischer Lexikon: staat und politik. Frankfurt am Main: Fischer Verlag, 1964. p. 220-226. 1962. . The structural transformation of the public sphere, Cambridge, Polity Press,

Zwischen Naturalismus und Religion: Philosophische Aufsätze (ZNR). Frankfurt am Main: Suhrkamp, 2005.

PETERS, Bernhard. Deliberative Öffentlichkeit. In: WINGERT, Lutz; GÜNTHER, Klaus (eds.). Die Öffentlichkeit der Vernunft und die Vernunft der Öffentlichkeit: Festschrift für Jürgen Habermas. Frankfurt am Main: Suhrkamp, 2001. p. 655-677. 